\title{
Student nurses' thinking during medication administration
}

\author{
J oyce Simones ${ }^{1}$, Diana Odland Neal ${ }^{2}$, Vicki Schug ${ }^{3}$, Linda M. Blazovich ${ }^{3}$, Cynthia Pivec $^{3}$, Jessie \\ Daniels ${ }^{4}$, Mary Kay Becker ${ }^{5}$, Cathy Schulenberg ${ }^{3}$, Suzanne M. Lehman ${ }^{3}$, Kathleen A. Ohman ${ }^{6}$, \\ Paula Swiggum 7 , Pat Keller ${ }^{8}$
}

1. Department of Nursing, St. Cloud State University, St. Cloud, Minnesota, United States. 2. Department of Nursing, St. Olaf College, Northfield, Minnesota, United States. 3. Department of Nursing, St. Catherine University, St. Paul, Minnesota, United States. 4. Department of Nursing, National American University, Bloomington, Minnesota, United States. 5. Department of Nursing, Anoka Ramsey Community College, Coon Rapids, Minnesota, United States. 6. Department of Nursing, College of St. Benedict/St. John's University, St. Joseph, Minnesota, United States. 7. Department of Nursing, Gustavus Adolphus College, St. Peter, Minnesota, United States. 8. Department of Nursing, Globe University, Richfield, Minnesota, United States.

Correspondence: Joyce Simones. Address: Department of Nursing, St. Cloud State University, St. Cloud, Minnesota, 56301, United States. Email: jmsimones@stcloudstate.edu

Received: July 23, 2014

DOI : $10.5430 /$ jnep.v4n11p136
Accepted: September 8, $2014 \quad$ Online Published: September 26, 2014

URL: http://dx.doi.org/10.5430/jnep.v4n11p136

\section{Abstract}

Background: The thought processes of student nurses during medication administration relative to prevention of patient harm or errors or promoting therapeutic responses are not well known. Nursing students may be focused more on the rules and procedures rather than anticipatory problem solving and concurrent patient teaching that occurs with practicing nurses. The Quality and Safety Education for Nurses (QSEN) project provides nursing faculty with a framework to assure that graduates are able to demonstrate quality and safety competencies, including that of medication administration.

Methods: This qualitative study examined student nurses' reported thinking during medication administration in a simulated experience involving care of a post-operative patient reporting pain. Forty-eight students from 5 baccalaureate nursing programs participated in a video recorded simulation with a standardized post-operative patient. Students independently completed a patient assessment and administered pain medication from a variety of options. Following the simulation, semi-structured debriefing interviews containing 8 open-ended questions were conducted and audiotaped.

Results: Students administered a variety of pain medication during the simulation. Analysis of transcriptions revealed five themes including 1) safety, 2) clinical reasoning, 3) uncertainty and need for validation, 4) lessons learned, and 5) perception of realism. Safety was the most predominant theme that emerged from the data.

Conclusion: Students must be able to more fully understand clinical decision making around medication administration (e.g., best practice, individual experiences with pain, patient preferences, patient conditions, etc.). Implementing teaching strategies that integrate opportunities for several valid nursing interventions encourage students to move away from a linear perspective to examine their thinking and the complexity of clinical practice. Findings will inform faculty relative to curricular design, pedagogy, and evaluation in educating nursing students to become safe and competent nurses.

\section{Keywords}

Thinking processes, Decision making, Nursing students, Simulation, Medication administration 


\section{I ntroduction}

Patient safety and quality care are issues of major concern worldwide and are significant challenges facing healthcare systems, clinical practice, and nursing education. The Quality and Safety Education for Nurses (QSEN) project, funded by the Robert Wood Johnson Foundation, has been pivotal in engaging nursing faculty in the important work of assuring that graduates are able to demonstrate quality and safety competencies. The purpose of the QSEN project is to prepare nurses who will improve the quality and safety of the healthcare system and individual performance ${ }^{[1]}$. To promote quality and safety in nursing care, QSEN developed core competencies in knowledge, skills, and attitudes (KSAs) that are essential for pre-licensure nursing students. Medication administration is a common and necessary core competency in nursing care. Patient safety is especially at risk during medication administration as medication incidents are a leading cause of patient injury ${ }^{[2]}$.

Nursing educators face many challenges ensuring that students have the knowledge and abilities to safely administer medications to patients. The simulation nursing lab is a safe environment to teach medication administration. Repetition and rote memory have traditionally been used heavily by students to acquire nursing skills such as medication administration. Although the procedure of administering medications appears to be simple and straightforward from a psychomotor domain, the student nurse's thought processes and critical judgments may contribute to medication errors. The thought processes of student nurses during medication administration related to prevention of patient harm or errors or promoting therapeutic responses are not well known.

\section{Relevant scholarship}

Safety in student nurse medication administration is an area that has been explored by nurse researchers. While studies have revealed factors contributing to student medication errors and some addressed student concerns about patient safety during medication administration, few have included the perceptions and thinking processes of student nurses and none specifically reported student thinking immediately after the administration of medications.

Three categories of student medication errors were identified by Cooper ${ }^{[3]}$ and Harding et al. ${ }^{[4]}$ : a) errors related to medication administration rights, b) system factors, and c) gaps in student knowledge. In a descriptive, retrospective study of medication errors linked to the practice of 1,305 students during a five year period of time, Wolf et al. ${ }^{[5]}$ identified various types of errors including: a) inaccurate dose (31.25\%), b) omission error (19.00\%), and c) wrong time (16.93\%).

Causes of medication errors were also explored by Wolf et al. ${ }^{[5]}$, who found that the most prevalent cause of medication errors was students' performance deficits (51.01\%) followed by students not following procedures/protocols (31.89\%), knowledge deficits (26.52\%), and communication (16.92\%). Lack of knowledge was discussed by Vaismoradi et al. ${ }^{[6]}$, Sulosaari et al. ${ }^{[7]}$ and Honey and Lim ${ }^{[8]}$ as well, in addition to self-confidence. Honey and Lim ${ }^{[8]}$ also identified lack of communication as a prevalent cause of student errors along with several other causes such as: a) lack of time to process knowledge and look up drugs in clinical, b) lack of opportunity to practice decision-making regarding medication choices because nurses make those decisions, c) information overload, and d) feeling overwhelmed and stressed in clinical. Likewise, information overload and feeling rushed were attributed as causes for student errors by Krautscheid et al. ${ }^{[9]}$. Inexperience (77.71\%) and distractions (20.03\%) were determined to be the leading contributing factors to student medication errors by Wolf et al. ${ }^{[5]}$. Krautscheid et al. ${ }^{[9]}$ also ascribed distractions as contributing to student errors.

Human and system failures as well as poor adherence to the five rights were stated as the major causes of medication administration errors in a research study with 329 junior and senior nursing students. Valdez et al. ${ }^{[10]}$ maintained that human failures included students' performance deficits and that system failures involved circumstances where students and staff were both assigned to provide care for the same patients, stress due to workload, or staffing problems, etc. Only poor adherence to the five rights was found to have a direct impact on medication errors made by students. 
In a pharmacologic simulation case scenario and debriefing with 72 students, Thompson and Bonnel ${ }^{[11]}$ reported that, although the students could accurately answer questions relative to narcotic administration on a written medication examination, when administering medications during a high fidelity patient simulation, all student groups failed to check the narcotic dosage and all groups administered an overdose. Consequently, the physiologic status of the simulated patient declined and the students had to obtain a verbal order for and administer an antidote.

In a randomized controlled study, Sears et al. ${ }^{[12]}$ found that simulation contributed to the success of student nurses in overcoming the risks of error and increased their safety in medication administration. Debriefing following the simulated obstetric and medical surgical scenarios revealed that students lacked prior experience with the situation, which hindered their performance; thus, students were given the opportunity to reinforce their knowledge and attempt the simulation again. There was significant evidence that the student group who had the simulation-based experience had fewer medication errors during their actual clinical experience than the control group. Helyar et al. ${ }^{[13]}$ also identified simulation to be an effective means for student exploration of medication administration and prevention of errors. These findings are consistent with research completed by Alinier et al. ${ }^{[14]}$, which demonstrated greater improvement in performance by students exposed to simulation training.

Although nurse researchers did not provide information related to what students were thinking while administering medications, some did report that students and new graduates expressed concern about patient safety ${ }^{[6,9,11,13,15]}{ }^{\text {. Student }}$ comments during Thompson and Bonnel's ${ }^{[11]}$ pharmacologic simulation debriefing and evaluation indicated, "they had learned a valuable lesson [about medication administration] in a safe environment.” In a qualitative questionnaire following a medication administration scenario, Andrew and Mansour ${ }^{[15]}$ also reported student concerns related to their experiences with patient safety. Third year nursing student responses encompassed four themes: a) protecting patient safety (actions they would take to protect patients from errors), b) willingness to compromise (or act outside the boundaries of correct medication procedures or policies), c) avoiding responsibility (not wanting to get involved in medication errors or accepting that potential errors may happen to them), and d) consequences resulting from actions (concern that there may be penalties or backlash if they report unsafe practices).

Few studies explored the perceptions/thinking processes of student nurses related to medication administration. Student perceptions about factors contributing to errors in administering medications included: a) too much time between medication administration theory and practice, b) deficient education in applied pharmacology, c) lack of practice, and d) little time for reflection upon medication administration experiences ${ }^{[6]}$. Nursing students also described feeling prepared to administer medications, but did not describe the thinking involved to administer drugs safely ${ }^{[5]}$.

Using two hypothetical case vignettes of patients in pain, Briggs ${ }^{[16]}$ examined the thought processes of junior and senior nursing students who assessed the patient's pain and made decisions regarding analgesic administration. Findings showed that, although more than half of the students in the sample assessed the patients' pain accurately, many were influenced by behavioral factors and undertreated the patients' reported pain level. This finding is consistent with studies conducted by Baxter and Boblin ${ }^{[17]}$ and Garrett ${ }^{[18]}$, which uncovered factors that influenced nursing students' decision-making in baccalaureate nursing programs.

Herm et al. ${ }^{[19]}$ developed a simulation scenario to evaluate the decision-making of nursing students during medication administration. They found that students previously thought to possess accurate critical thinking skills, sound decisionmaking ability, and clinical competence failed to recognize significant clinical data.

Overall, the studies revealed that numerous factors contribute to student nurses making errors in medication administration including: a) failure to use medication administration rights, b) system factors, c) gaps in knowledge, d) performance deficits, e) lack of time to process knowledge, f) lack of time to look up drugs, g) lack of practice for medication administration skills and decision-making regarding medication choices, h) lack of confidence, i) information overload, j) feeling overwhelmed and stressed, k) lack of self-confidence, l) inexperience, $\mathrm{m}$ ) distraction, n) poor adherence to the 
five rights, o) too much time between medication administration theory and practice, p) deficient education, and q) little time for reflection upon medication administration experiences ${ }^{[3-19]}$. How students think during the medication administration process was not specifically addressed. Given these findings, the research team decided to more fully explore student thinking during medication administration within the context of a simulation.

\section{Method}

\subsection{Sampling procedure}

A convenience sample of senior nursing students in five baccalaureate programs in a Midwestern state were invited to participate in the study. Study sites included three private liberal arts universities/colleges, a state university, and a proprietary institution. A cover letter and consent form explaining the purpose of the study were distributed to the students. Inducements for participation in the study were not offered to the students. Members of the research team did not know which students agreed or did not agree for participate. Of the students who agreed to participate, 8 to 10 students from each program were randomly selected. The sample consisted of 48 students. The study was approved by each program's institutional review board (IRB). All students had successfully completed a semester in adult medical-surgical nursing and had been evaluated in medication administration through psychomotor skills testing.

\subsection{Participant characteristics}

The majority of the sample was female (85\%), with $81 \%$ of students between age 19 and 25 . Only $10 \%$ of the sample was non-white, including African-American, Asian, and Hispanic ethnicities. Of the sample, 31\% reported completing a summer internship and $44 \%$ reported experience as a certified nursing assistant. There was one licensed practical nurse.

\subsection{Research design}

A descriptive qualitative design described by Polit and Beck ${ }^{[20]}$ was utilized to address the research question: What are student nurses' reported thinking processes during medication administration? This qualitative approach employed a simulated clinical experience followed by a semi-structured taped debriefing interview. The study design was adapted, in part, from a study of practicing nurses conducted by Eisenhauer et al. ${ }^{[21]}$.

A pilot study was conducted to standardize procedures and instructor guidelines at each research site. Consistent equipment and supplies including the medication dispensing system were utilized. The scenario included the patient's history, primary medical diagnoses, medication administration record, and a written change of shift report. The standardized patient was one day post-operative following a total hip arthroplasty with a reported pain level of 6 on a 0 to 10 numeric pain scale. There were several analgesics prescribed for pain control - Morphine, Tylenol, and Toradol, with one incorrect choice (Tylenol \#3 as the patient had a codeine allergy). A patient script was developed to provide consistent responses to anticipated questions.

\subsection{I ntervention}

Each student participant was provided with materials outlining the learning objectives and performance expectations one week prior to the simulated clinical experience. At the simulation, each student was given 10 minutes for preparing and reviewing a written shift-to-shift report. During the 20 minute video-taped patient interaction, the student implemented nursing interventions including medication administration based on assessment findings. The student was instructed to verbalize his/her decision making process in determining which pain medication(s) to administer. After the scenario, each student was escorted to a private room for a 15 minute debriefing session. A faculty script of eight questions (see Table 1) was created for the semi-structured individual debriefing to elicit the student's thinking during his/her preparation and administration of medications. 
Table 1. Debriefing questions

Welcome to the debriefing room. The purpose of the debriefing is to understand what you were thinking when you were preparing and administering the medication. I will be asking you a series of questions. There is no right or wrong answer. Some questions may seem redundant, but please answer each question thoroughly. Do you have any questions before we begin?

1) How did you prepare for this simulation?

2) Take me through your steps of medication administration, beginning with when the pain medication was requested.

3) What did you need to know to give the medication?

4) What questions were raised in your mind during the medication simulation experience?

5) There were several choices of pain medication. Describe your thinking process when you made the choice to give the medication.

6) What, if anything, would you do differently?

7) What additional information would have been helpful to know about this situation?

8) How might this simulation impact your administration of medications in the future?

Thank you for participating in this research project. For research purposes, we ask that you do not share any of this scenario or anything that happened or was discussed with any other students because this could influence the results of the research.

\subsection{Data analysis}

Audiotapes of students' debriefing were transcribed verbatim. To uncover the genuine experience of student thinking during medication administration, Colaizzi's ${ }^{[22]}$ method was used to analyze the audiotapes. First, students' descriptions of the experiences were read in order to acquire a sense of students' thinking. Next, significant statements were extracted. Meanings were then formulated from the significant statements and organized into themes. Triangulation was used to establish validity by the use of several investigators, different times, and locations ${ }^{[23]}$. Two researchers experienced in performing content analysis, established inter-rater reliability by individually reviewing each transcript to identify the common themes. These themes were integrated into descriptions to explain the thinking processes of nursing students during medication administration. For validation, a selected subgroup of participants evaluated the result of the analysis for congruency with their original experiences. Final themes were compared to the literature.

\section{Results}

Students administered a variety of pain medications to a patient in the simulation scenario who reported a pain level of 6 on a 0 to 10 scale. Thirty-seven of the 48 students gave single medications (see Figure 1). The most common single medication given was Toradol $15 \mathrm{mg}$ IV, which 12 of the students administered. Eleven of the students gave multiple medications ranging from one oral Toradol $20 \mathrm{mg}$ and one oral Tylenol $325 \mathrm{mg}$ to Morphine $4 \mathrm{mg}$ IV, Toradol $15 \mathrm{mg}$ IV, and one oral Tylenol 325 mg (see Figure 2).

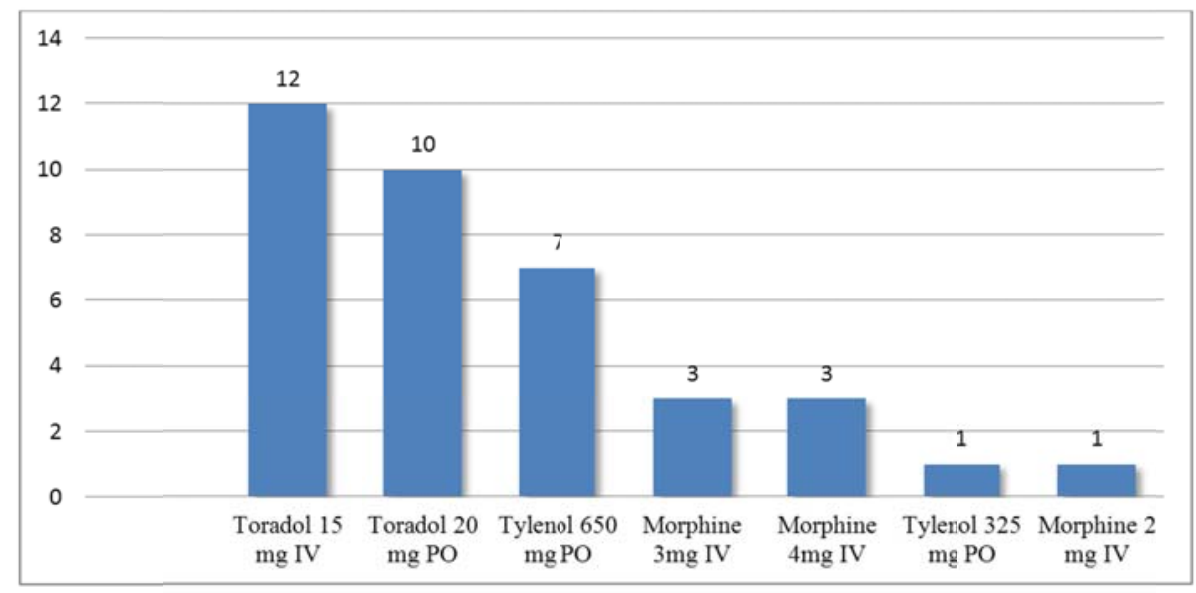

Figure 1. Single medication administered 


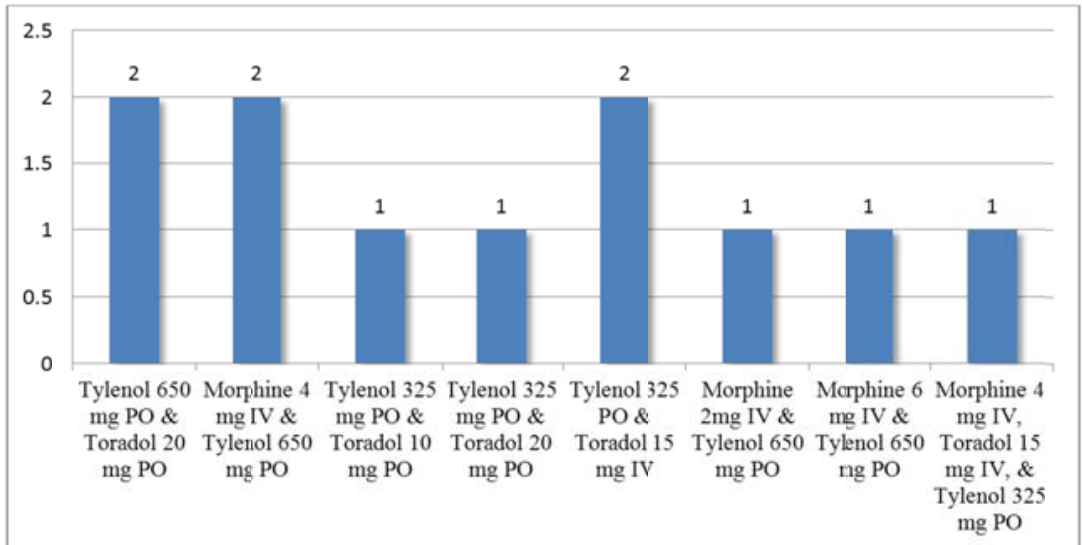

Figure 2. Multiple medications administered

\section{Themes from transcribed student interviews}

\section{Safety}

Safety was the most predominant theme expressed throughout student transcripts. Students were systematic about preparing medications for administration: "making sure each step was followed," "making sure to look up every single medication," "making sure that the dosing was right," any possible side effects it may have and "double checking”, "triple checking," "quadruple checking everything." One student declared: "I would check everything about the medication to make sure there wasn't any allergies....and make sure that the last time she had the medication, ....and that it was in the accepted four hour range [of waiting].”

Several students were concerned about overmedicating their patient "I wanted to make sure I was not over medicating her ... looked at meds she had been given to not overdose her for the day... looked at what I could and could not give her... what contraindications she may have with other drugs. I needed to know how the drug works... why it does what it does... what kind of classification it is.... Her respirations and $\mathrm{O}_{2}$ sats were down....”

A few students recognized when they made mistakes and wanted to make sure they did not occur again: "Somehow I messed up with the conversions and I was thinking it was $1 \mathrm{~mL}$ per 1 milligram. So that's where I need to go back and do some further research myself and better myself to make sure those errors do not happen.”

\section{Clinical reasoning}

Students discussed the importance of thinking about why a certain medication would be given. An example of clinical reasoning was expressed by one student: "It's not always about just giving what the last person gave... and it means that you have to look at, what is their pain,... kind of out weighing the pros and cons of giving the meds. It's important... if someone had been giving $4 \mathrm{mg}$ and then they have a pain of 8 or $9 \ldots$ you don't want to give $2 \mathrm{mg}$. You want to stay on top of the pain. You don't want to let their pain get worse.”

Choosing among multiple medication options was a new skill for many students, "I never had to choose between giving one drug over the other, so I kind of questioned myself about the benefits of giving morphine over Toradol and vice versa." "I knew that as I was doing it that I did not have a handle on why I was selecting... what I was selecting." "It helps me realize that there's going to be several options and you need to weigh each option. And there might be more than one good answer or medication to give, but there's one that will be more right."

Students reported various rationales for administering their medication of choice. Many of the students looked at medications previously given: "I looked at what she had previously been given over the last 24 hours. I then compared it to what I had investigated as far as the medications go." 
Many students used deductive reasoning or ruling out certain medications in their decision making process: "I chose to give the Toradol and I chose to give it IV because the patient had a pain level of 6 . Choosing the IV over the PO form of Toradol was because of the patient's rating. IV gets on board faster than oral meds. I chose to give the oral acetaminophen to combat the patient's climbing fever she was running. I chose not to give the Tylenol 3 due to the fact that the patient has codeine allergies. Codeine is a component of Tylenol 3. I chose not to give morphine because of the respiratory status of the patient. The respiratory rate being less than 10 at 0800 . Typically, when a patient has codeine allergies, you can still give morphine because codeine is actually metabolized into morphine and not vice versa, however, in severe anaphylactic reactions, like the patient described with a codeine allergy, doctors have conflicting opinions about administering morphine.”

The patient response was the reason that some students chose the medication, "Simply, I go by the patient's response. If the level is above or greater than a 4, I always would think to do the IV route first just because, it’s quicker.”

Eleven students gave multiple medications: "I looked and chose the morphine .... Also, she had been given Tylenol which I thought was also a good idea, because also it could help with the pain and it might bring her fever down a little bit." "Recognize that some medications can ... kill two birds with one stone, like try to drop her temperature a little bit, and do her pain medication.”

Other factors that students considered were: (1) sedation level of the patient, (2) presence of bowel sounds, (3) ability to take oral medications, (4) intake of food, (5) presence of nausea, (6) alleviating and aggravating factors, (7) any contraindications, (8) post-op day one status, (9) response to medications given during the night, (10) how painful the procedure was, and (11) how familiar the student was with the medication.

\section{Uncertainty and need for validation}

Students had limited clinical experience in administering medications. For this reason, most students questioned themselves and expressed uncertainty in their medication choice(s). "I feel like when you're using your nursing skills regularly, it's very much on your brain.” Other students conveyed wanting more experience or practice to sharpen their skills: "I need a lot of work on just... the administration of meds; injections, IV injections, piggybacks, checking IV site... all of it. I need to spend a lot of time on that. I did not have an internship over the summer, so I have only done what we have done in lab and last year in clinical.”

Students discussed having a broad range of feelings during the simulation experience from, "I felt that it went really well" to "a bit nervous \& anxious... I'm happy that it is over." Some students found themselves questioning everything, yet others were confident. For example, one less confident student said, "I felt a little alone in making that decision." Another stated: "I felt uncomfortable... this experience made me think in new way... I would so love to have a little bit more time to prep and then do it again... I did not know what to expect.”

Students wanted to be sure that they did everything right and didn't make any mistakes; therefore, they questioned each medication administration decision they made. One student commented: "I was worried about the actual picking of which medication that I wanted and if that was really the best choice to be injecting... so kinda like a self-questioning." Others simply tried to think about every possible question they could think of in relation to medication administration: "Was I choosing the right med? Was I administering it properly? Was I aware of what to look for after I administered it? Was I accessing it properly? Was I getting it ready properly? Was I going to give it to her properly?”

Students often expressed a desire to be in communication with another health care professional. Several students would have liked to call the pharmacist, physician, or to talk with the nurse from the previous shift, or have more documentation to validate their decision(s): "Seeing that I am a new nurse, I would have wanted the second opinion of a colleague. So I would have double-checked with another nurse that was on the floor." 


\section{Lessons learned}

Students reported learning many lessons from the simulation experience: "I see a couple of mistakes that I made, I will focus on those things when I practice .... I guess you always learn from your botches so you don't do them again... hopefully." "No matter what time of the day it is. I will always, always, always check the dosage to make sure you are giving the right amount to the right patient... the five rights.”

Students realized that medication orders are not always correct: "And also to just again be mindful of the fact that physicians sometimes prescribe drugs that interact negatively with the patient. For example, Tylenol 3 was prescribed, but the patient was allergic to codeine.”

A student also described the importance of assessing for effects of medication upon patients: "I will have to think deeper about the pain meds and the interactions of what's going on with the patient at the time... because she has pain, you know, a while ago. My first thought would be to give her a pain med, but you have to look at the whole picture. Respirations, allergies... a stomach ache at the time, so I guess this just further proves that you need to think about each med administration and how it affects the person as a whole.”

Including the patient in the decision making process was another valuable consideration stated by one student: "I realize how important it is to have the patient rate their pain, because it gives you a basis ... to choose your intervention. And to make sure that you take your time and really ask the questions that you need to make the appropriate decision. And be sure to come back and check on the patient after you have given the medication."

Reflection is an important part of learning and cognitive development. Students reflected on the value of the simulation and their thoughts and actions related to the experience. Practice was an important part of learning: "I would like to do it a thousand more times because, as much as it is uncomfortable, it is forcing me to think in a way that I am not used to or comfortable with yet. It is okay that I feel uncomfortable; I would just like to do this a lot if I had the chance.”

\section{Perception of realism}

Students discussed the impact of the realistic nature of the simulation on their thinking. Comments included "[It was] more like trying to walk through the steps because you guys obviously don't have a real patient in there.....and making sure I did all those steps instead of just pretending it's a med in a little box.” Another student commented, "The simulation also feels real and the emotional experience of giving drugs and not being $100 \%$ sure is scary.”

Students had difficulty not knowing all the information about the patient in the simulation: "If I had been in this situation for real life, you would have known the patient a little more...” Many of the students had experienced previous simulation test outs in the past where they had to identify what was wrong or inappropriate in the simulation: "I thought it was going to be a little more complex. I thought there might be something hidden, something wrong with her that we were supposed to find out and treat.”

\section{Discussion}

The purpose of this study was to examine student thinking during a simulated medication administration scenario. Safety was the most predominant theme that emerged from the data. Safe administration of medications by students is a goal of nursing education. Since QSEN defined safety and identified safety competencies, educators are charged to increase the students' focus on safety. This study supports student recognition of this critical nursing competency in order to "minimize risk of harm to patients through both system effectiveness and individual performance” ${ }^{[1]}$.

This study also supports the findings that safe medication administration is more than a technical, mechanical process ${ }^{\text {[21] }}$. Student comments in this study affirmed the requisite knowledge, skills, and attitudes needed for safety relative to patient 
assessment and administration of medications. Students recognized that as practitioners with limited experience at the novice or advanced beginner level, extensive measures including clinical reasoning are necessary to prevent errors. Additionally, greater proficiency and enhanced competency will occur with more practice.

Students verbalized a wide range of emotional responses to the simulation experience. Many of these responses were related to feelings of uncertainty and needing validation in relation to their thinking and performance. Factors identified by students as influencing their level of confidence included the amount of previous clinical experience and the perception of insufficient knowledge or insufficient information to make an informed decision. The connection between confidence and clinical performance ${ }^{[7]}$ was supported by the findings of this study. Students repeatedly drew connections between their level of confidence and their perceived performance. Some students noted that previous clinical experience and internships gave them greater confidence in completing the simulation; however, students still verbalized the desire for outside validation from faculty and clinical nursing staff to discuss and affirm their decision making. This finding was consistent with Garrett ${ }^{[18]}$ who noted that students felt validation from other members of the nursing team was necessary to make effective decisions.

During the simulation debriefing, students reported a number of "lessons learned" relative to questioning physician's orders and learning from one's mistakes. The simulation experience afforded students the opportunity to reflect on their performance in the context of safety, accountability and the potential consequences of making an error. This study's findings concur with Helyar et al. ${ }^{[13]}$ in that students questioned their practice and highlighted their vulnerability to medication administration error.

Numerous studies have illustrated the importance of realism in simulation in student development of critical thinking and decision making skills ${ }^{[11,14,19]}$ Participants in this research acknowledged the effectiveness of the simulation in helping them reflect on their confidence and performance related to medication administration and management of complex patient situations, but some students stated they would react differently in a "real" clinical situation and questioned the authenticity of the simulation set up. This differed from faculty perception that the simulation experience accurately reflected actual clinical practice. Nevertheless, this finding underscores the importance of maintaining a high level of realism when setting up and conducting simulation experiences. Sears ${ }^{[12]}$ note that fewer medication errors have been reported if students have had a prior medication simulation experience or a related simulation experience. The authors conclude that by increasing clinical and simulation experiences, education can better prepare safe nurses for practice.

\section{Limitations}

There were several limitations to this study. Although the students at each site had completed their first adult medicalsurgical nursing clinical course, each baccalaureate nursing program's curricular design is unique. The study findings may have been influenced by the program's varying curricular content and associated clinical experiences. Although procedures were implemented to include common information and practices used in all five academic institutions, some variability in student resources was discovered. One specific example noted was the variation in drug resource books, resulting in differences in recommended dosages of ketoralac (Toradol ${ }^{\circledR}$ ). Additionally, a potential for inconsistency existed due to the implementation of the research procedure occurring at different times during the year and at five locations with variation in the simulation room and equipment setup, role-players, and debriefers.

A major challenge in studying thinking processes is the difficulty of recall and the rapidity and multitasking nature of participants' thinking, especially in a fast-paced and constantly changing clinical environment ${ }^{[13]}$. The same held true in this research. Students were requested to articulate the process of their critical thinking/decision making during a time limited debriefing experience. During the debriefing, researchers were not able to ask follow-up questions to elicit clarification, which may have facilitated additional reporting of thinking. Additionally, full disclosure of student thinking may not have occurred if there was a perception of errors in thinking during the simulation experience. 
The emotional component during the simulation that was reported by students during the debriefing may have interfered with their ability to recall specific details of patient interactions, information seen in the medical record, or the sequence of steps completed during the medication administration (e.g. anxiety, worry about missing something, suspicion of "being tricked"). As one student reported, "the simulation also feels real and the emotional experience of giving drugs and not being $100 \%$ sure is scary.” Also, student performance was video-recorded to reflect practices used for psychomotor skill testing, and this may have contributed to student anxiety as well.

Triangulation helped to assure validity and enhance rigor of the study. This was completed through member checking and analysis with a small subset of the student sample. Students validated that the thematic analysis was accurate and captured the essence of the simulation experience.

\section{I mplications and conclusions}

In order to prevent medication errors, research needs to focus on student thinking during medication administration. Such an understanding might lead to nursing education to correct student thinking prior to student administration of medications to patients. Nursing education programs typically introduce concepts of safe medication practice early in the curriculum and continuously integrate this knowledge into the classroom theory sessions, nursing laboratory experiences, and clinical settings. Medication administration knowledge is often evaluated using psychomotor skills testing. Isolated medication skills testing relies heavily on rote memorization and offers few opportunities for students to demonstrate clinical decision making within the context of a simulated patient situation. Simulations that encourage students to choose a single correct answer often reinforce the misconception that there is only one right answer. Simulation scenarios that offer several decision pathways encourage students to prioritize and support their decisions while simultaneously introducing them to the complex thinking necessary for effective clinical decision making. Implementing simulations that integrate opportunities for several valid nursing interventions encourage students to move away from a linear perspective and begin to explore their thinking and the complexity of clinical practice.

\section{Acknowledgement}

Gustavus Adolphus College Faculty Development Grant; Kappa Phi-at-Large Chapter of Sigma Theta Tau International; St. Catherine University Academic Community Development Committee; College of St. Benedict/ St. John's University Faculty Development and Research Grant.

\section{References}

[1] Cronenwett L, Sherwood G, Barnsteiner J, Disch J, Johnson J, Mitchell P, Sullivan DT, Warren J. Quality and safety education for nurses. Nursing Outlook. 2007; 55(3): 122-131. PMid:17524799 http://dx.doi.org/10.1016/j.outlook.2007.02.006

[2] Institute of Medicine. Preventing medication errors. Washington, DC: National Academy Press. 2007 Available from: http://www.hc-sc.gc.ca/dhp-mps/medeff/cmirps-scdpim-eng.php

[3] Cooper E. Nursing student medication errors: a snapshot view from a school of nursing's quality and safety. The Journal of Nursing Education. 2014; 53(3): S51-S54. PMID: 24512332 http://dx.doi.org/10.3928/01484834-20140211-03

[4] Harding L, Petrick T. Nursing student medication errors: A retrospective review. The Journal of Nursing Education. 2008; 47(1): 43-47. PMID: 18232615 http://dx.doi.org/10.3928/01484834-20080101-05

[5] Wolf ZR, Hicks R, Serembus JF. Characteristics of medication errors made by students during the administration phase: A descriptive study. Journal of Professional Nursing. 2006; 22: 39-51. PMid:16459288 http://dx.doi.org/10.1016/j.profnurs.2005.12.008

[6] Vaismoradi M, Jordan S, Rurunen H, Bondas T. Nursing students' perspectives of the cause of medication errors. Nursing Education Today. 2014; 34: 434-440. PMid:23669600 http://dx.doi.org/10.1016/j.nedt.2013.04.015

[7] Sulosaari V, Kajander S, Hupli M, Huupponen R, Leino-Kilpi H. Nurse students' medication competence - An integrative review of the associated factors. Nursing Education Today. 2012; 32: 399-405. http://dx.doi/ 10.1016/j.nedt.2011.05.016 
[8] Honey M, Lim A. Application of pharmacology knowledge in medication management by final year undergraduate nursing students. Contemporary Nurse. 2008; 30(1):12-19. http://dx.doi.org/10.5172/conu.673.30.1.12

[9] Krautscheid L, Orton V, Chorpenning L, Ryerson R. Student nurse perceptions of effective medication administration education. International Journal of Nursing Education Scholarship. 2011; 8(1): 1-15. http://dx.doi.org/10.2202/1548-923X.2178

[10] Valdez LP, Guzman A, Escolar-Chua R. A structural equation modeling of the factors affecting student nurses' medication errors. Nurse Education Today. 2013; 33: 222-228. PMid:22325830 http://doi.org/10.1016/j.nedt.2012.01.001

[11] Thompson T, Bonnel W. Integration of high-fidelity patient simulation in an undergraduate pharmacology course. Journal of Nursing Education. 2008; 47(11): 518-521. http://dx.doi.org/10.3928/01484834-20081101-10

[12] Sears K, Goldsworthy S, Goodman W. The relationship between simulation in nursing education and medication safety. Journal of Nursing Education. 2010; 49(1): 52-55. PMid:19810664 http://dx.doi.org/10.3928/01484834-20090918-12

[13] Helyar S, Griffiths P, Norman IJ, “The damage I could do...”- Qualitative evaluation of a low-fidelity medication administration simulation that generates error as a learning experience for pre-registration nursing students. Journal of Nursing Education and Practice. 2014; 4(2): 11-19.

[14] Alinier G, Hunt B, Gordon R. Determining the value of simulation in nurse education: study design and initial results. Nurse Education in Practice. 2004; 4(3): 200-207. http://dx.doi.org/10.1016/S1471-5953(03)00066-0

[15] Andrew S, Mansour M. Safeguarding in medication administration: understanding pre-registration nursing students' survey response to patient safety and peer reporting issues. Journal of Nursing Management. 2014; 22: 311-321. PMid:23919661 http://dx.doi.org/10.1111/jonm.12134

[16] Briggs CL. What were they thinking? Nursing students' thought processes underlying pain management decisions. Nursing Education Perspectives. 2010; 31(2): 84-88. PMid:20455363

[17] Baxter PE, Boblin S. Decision making by baccalaureate nursing students in the clinical setting. Journal of Nursing Education. 2008; 47(8): 345-349. http://dx.doi.org/10.3928/01484834-20080801-02

[18] Garrett B. Student nurses' perceptions of clinical decision-making in the final year of adult nursing studies. Nurse Education in Practice. 2005; 5: 30-39. PMid:19038176 http://dx.doi.org/10.1016/j.nepr.2004.03.003

[19] Herm SM, Scott KA, Copley DM. “Sim” sational revelations. Clinical Simulation in Nursing Education; 2007; 3(1): 25-30. http://doi.org/10.1016/j.ecns.2009.05.036.

[20] Polit DF, Beck CT. Nursing research: Generative and assessing evidence for nursing practice (8th ed.). Philadelphia, PA: Wolters Kluwer/Lippincott Williams \& Wilkins; 2008; 237-238.

[21] Eisenhauer LA, Hurley AC, Dolan N. Nurses’ reported thinking during medication administration. Journal of Nursing Scholarship. 2007; 39(1): 82-87. PMid:17393971 http://dx.doi.org/10.1111/j.1547-5069.2007.00148.x

[22] Colaizzi PF. Psychological research as the phenomenologist views it. In R. Valle \& M. Kings (Eds), Existential phenomenological alternative for psychology. New York, Oxford University Press. 1978; 48-71.

[23] Creswell JW. Qualitative Inquiry \& Research Design: Choosing Among Five Approaches (2nd ed.). Thousand Oaks, CA: Sage; 2007. 